\title{
Brønsted and Lewis acidity of modified montmorillonite clay catalysts determined by FT-IR spectroscopy
}

\author{
C. Ravindra Reddy ${ }^{a}$, Y.S. Bhat ${ }^{\text {a }}$, G. Nagendrappa ${ }^{\text {b }}$, B.S. Jai Prakash ${ }^{\mathrm{a}, *}$ \\ a Department of Chemistry, Bangalore Institute of Technology, KR Road, Bangalore 560004, India \\ ${ }^{\mathrm{b}}$ Department of Chemistry, Bangalore University, Central College Campus, Bangalore 560001, India
}

A R T I C L E I N F O

\section{Article history:}

Available online 7 July 2008

\section{Keywords:}

Montmorillonite

Acidity

Cation-exchanged clays

Al-PILC

Esterification

\begin{abstract}
A B S T R A C T
The surface acidity of different modified montmorillonite clay catalysts, $\mathrm{Al}^{3+}$-exchanged montmorillonite $\left(\mathrm{Al}^{3+}\right.$-Mont) and aluminium pillared montmorillonite (Al-PILC) was determined by DRIFTS (diffuse reflectance Fourier transform infrared spectra) using pyridine as probe molecule. The method involved treating the clay sample directly with pyridine, drying the sample at $120{ }^{\circ} \mathrm{C}$ and recording FT-IR spectra in the region 1650 and $1350 \mathrm{~cm}^{-1}$. The spectra obtained showed well resolved absorption bands for Lewis and Brønsted acid sites in the clay catalysts. In order to understand the role of acid sites present on clay catalysts, esterification of propionic acid with $p$-cresol has been studied. The Brønsted acidity data obtained by FT-IR study for modified montmorillonite clay catalysts correlated well with the catalytic activity in the esterification reaction. Among the modified clay catalysts, $\mathrm{Al}^{3+}$-Mont and $\mathrm{H}^{+}$-Mont clay catalysts showed good activity and Al-PILC showed negligible activity in esterification. The inactivity of Al-PILC catalysts is attributed to the absence of Brønsted acidity.
\end{abstract}

(C) 2008 Elsevier B.V. All rights reserved.

\section{Introduction}

Acidity on catalyst surface plays an important role in bringing about various organic transformations. The origin and nature of acidity in zeolites and oxide surfaces have been studied and understood well [1-3]. The nature of acidic sites in clays is different from that of metal oxides and zeolites. The study of acid centers on clays is still a subject of investigation primarily because of the presence of different kinds of water molecules and their indefinite contribution to different types of acidities on the surface.

There are several methods to determine the surface acidity of clay minerals such as Hammett indicator technique [4], nbutylamine back titration [5], microcalorimetry [6] and FT-IR spectroscopy of adsorbed basic probe molecules [7-9]. Thermal desorption analysis of bases, such as butylamine, cyclohexylamine and pyridine, can also be used for rapid evaluation of the amount and type of acid sites in clay minerals [10]. Another widely used method to study the surface acidity of a solid catalyst is through the product distribution analysis of some model catalyzed reactions [11]. Isomerisation, catalytic dehydration, and dehydrogenation are the most common typical model reactions used for investigating the acid-base properties of heterogeneous catalyst systems [12,13].

\footnotetext{
* Corresponding author. Tel.: +91 80 26613237; fax: +91 8022426796.

E-mail address: jprak27@yahoo.com (B.S. Jai Prakash).
}

Brønsted and Lewis acid sites can be distinguished from the IR spectrum of pyridine adsorbed on the clay surface. The spectrum shows well resolved and characteristic bands for pyridine adsorbed on both the types of acid sites [14]. The methods used by earlier workers to study the acidity by IR measurements on pyridine adsorbed surfaces are tedious, which include preparation of very thin self-supporting wafers of the catalyst material under high pressure and then exposing the wafer to pyridine vapour at room temperature followed by desorption of physisorbed pyridine at $100{ }^{\circ} \mathrm{C}$ under high vacuum [15-17]. Recently, Jankovic and Komadel reported a relatively simple procedure to access Brønsted and Lewis acidity of clay catalysts [9]. In the present study, the method that is employed is similar to the method adopted by Jankovic and Komadel but is further simplified by treating the catalyst samples directly with pyridine and recording the spectra after thermal desorption of physisorbed pyridine at $120^{\circ} \mathrm{C}$. The main objective of this paper is to examine whether the acidity measured by the simplified method correlated with the activity of in the esterification of propionic acid with $p$-cresol.

\section{Experimental}

\subsection{Clay materials}

The clay mineral used in this work is a smectite rich white montmorillonite GK-129 (Na-GK, provided by Ceramic Technological Institute, Bangalore, India). The composition of the white 
montmorillonite was found by XRF to be $67.26 \% \mathrm{SiO}_{2}, 13.42 \%$ $\mathrm{Al}_{2} \mathrm{O}_{3}, 1.87 \% \mathrm{Fe}_{2} \mathrm{O}_{3}, 3.2 \% \mathrm{MgO}, 2.72 \% \mathrm{Na}_{2} \mathrm{O}, 1.27 \% \mathrm{~K}_{2} \mathrm{O}, 1.55 \% \mathrm{CaO}$, $0.09 \% \mathrm{TiO}_{2}, 0.02 \% \mathrm{MnO}, 0.07 \% \mathrm{BaO}, 0.03 \% \mathrm{P}_{2} \mathrm{O}_{5}, 0.89 \% \mathrm{~S}$, and $5.04 \%$ ignition loss. The cation exchange capacity (CEC) of montmorillonite was found to be $0.8 \mathrm{meq} \mathrm{g}^{-1}$. The enriched clay containing less than $2 \mu \mathrm{m}$ fraction was used for catalyst preparation. Commercially available acid clay, montmorillonite K-10 (procured from Sigma-Aldrich) was also used for comparative study in this investigation.

\subsection{Preparation of catalysts}

\subsubsection{Preparation of Al-exchanged clays}

The Al-exchanged montmorillonite clay was prepared by adopting standard procedure reported in the literature [18]. The method involves stirring $5 \mathrm{~g}$ of montmorillonite clay sample with $200 \mathrm{~mL}$ of $0.5 \mathrm{M} \mathrm{AlCl}_{3}$ solution for $24 \mathrm{~h}$. The clay was then centrifuged and washed with distilled water repeatedly until the washings showed negative test for chloride. The clay sample was then dried at $100{ }^{\circ} \mathrm{C}$ for $3 \mathrm{~h}$ and subsequently ground to a fine powder and used as $\mathrm{Al}^{3+}$-Mont (100) catalyst. In order to study the effect of thermal treatment on acidity as well as activity, the $\mathrm{Al}^{3+}$ Mont (100) was further thermally treated at $200{ }^{\circ} \mathrm{C}$ and $400{ }^{\circ} \mathrm{C}$ for $3 \mathrm{~h}$. The catalysts thus obtained were referred to as $\mathrm{Al}^{3+}$-Mont (200) and $\mathrm{Al}^{3+}$-Mont (400) respectively. However, in preparation of $\mathrm{H}^{+}$-Mont, $0.5 \mathrm{M} \mathrm{HCl}$ was used as a source of $\mathrm{H}^{+}$-ions and the rest of the procedure is same as followed above. Commercially available montmorillonite $\mathrm{K}-10$ was also modified into $\mathrm{Al}^{3+}$-exchanged form, which is labeled as $\mathrm{Al}^{3+}$-Mont $\mathrm{K}-10$. The procedure is similar to the one followed for the preparation of $\mathrm{Al}^{3+}$-Mont (100) catalyst except parent clay.

\subsubsection{Preparation of Al-PILC}

A solution of aluminium hydroxy oligomer cations was prepared by adding $0.4 \mathrm{M} \mathrm{NaOH}$ to $0.4 \mathrm{M} \mathrm{AlCl}_{3}$. The rate of addition of $\mathrm{NaOH}$ to $\mathrm{AlCl}_{3}$ was maintained at $1.0 \mathrm{~mL} \mathrm{~min}^{-1}$ and $\mathrm{OH}^{-} / \mathrm{Al}^{3+}$ ratio was maintained at 2.5 using peristaltic pump [19]. The resulting solution was aged for $24 \mathrm{~h}$ at ambient temperature ( $\mathrm{pH}$ 3.8). The aluminium oligomeric cations, formed under these conditions predominantly contained ions of Keggin-type $\left[\mathrm{Al}_{13} \mathrm{O}_{4}(\mathrm{OH})_{24}\left(\mathrm{H}_{2} \mathrm{O}\right)_{12}\right]^{7+}[20]$. The pillared clay material was prepared by stirring $1 \mathrm{~g}$ of clay sample with $125 \mathrm{~mL}$ of aluminium oligomeric solution for $12 \mathrm{~h}$. After pillaring reaction, the clay sample was separated by centrifugation and washed repeatedly with distilled water. Centrifugation and washing operations were continued till the washings show negative test for chloride ions. The resulting clay sample was dried at $100{ }^{\circ} \mathrm{C}$ for $4 \mathrm{~h}$ and ground to a fine powder and identified as Al-PILC (100). Finally, the Al-PILC (100) clay was calcined at $500{ }^{\circ} \mathrm{C}$ for $4 \mathrm{~h}$ and used as Al-PILC (500) catalyst.

\subsection{Methods}

XRD patterns of the clay samples were recorded on a Siemens D5005 diffractometer using $\mathrm{Cu} \mathrm{K} \alpha$ radiation source and a Ni filter. Basal spacings were calculated by making use of $d_{0} 0_{1}$ values. Specific surface area of clay samples was determined by BET methods at liquid nitrogen temperature using a Quantachrome NOVA 1000 surface area analyzer. Prior to the surface area analysis, the clay samples were degassed for $2 \mathrm{~h}$ at $100{ }^{\circ} \mathrm{C}$. The diffuse reflectance Fourier transform infrared spectra (DRIFTS) of modified montmorillonite clay catalysts were recorded in the spectral range $1650-1350 \mathrm{~cm}^{-1}$ using a diffuse reflectance accessory at room temperature on a Nicolet Avatar 320 FT-IR spectrometer.

\subsection{Catalytic study}

The liquid phase esterification reaction of propionic acid with $p$ cresol was carried out in $100 \mathrm{~mL}$ round-bottomed flask fitted with Dean-Stark trap for water removal and a reflux condenser. The flask was charged with propionic acid $(5 \mathrm{mmol}), p$-cresol ( $15 \mathrm{mmol}), 0.5 \mathrm{~g}$ of clay catalyst and $35 \mathrm{~mL}$ of toluene. The reaction mixture was refluxed for $8 \mathrm{~h}$, then cooled, filtered to separate the clay catalyst and the latter was washed with ethyl acetate $(2 \times 5 \mathrm{~mL})$. The combined filtrates were washed with $5 \%$ sodium hydroxide solution $(4 \times 15 \mathrm{~mL})$ to remove unreacted reactants. The organic layer was washed with water $(2 \times 15 \mathrm{~mL})$ and saturated brine $(1 \times 15 \mathrm{~mL})$, dried over anhydrous sodium sulphate. The solvent was finally distilled out under reduced pressure. The product was extracted with diethyl ether and identified by IR and ${ }^{1} \mathrm{H}$ NMR. The IR data of $p$-cresyl propionate $\left(\mathrm{cm}^{-1}\right)$ is $2983,1759,1585,1488,1075,915,753$ and 698 , and ${ }^{1} \mathrm{H}$ NMR data of compound is $1.26(\mathrm{t}, 3 \mathrm{H}), 2.3(\mathrm{~s}, 3 \mathrm{H}), 2.6(\mathrm{q}, 2 \mathrm{H}), 6.8(\mathrm{~d}$, $2 \mathrm{H})$ and $7.1(\mathrm{~d}, 2 \mathrm{H})$.

\subsection{FT-IR spectroscopic measurements}

The DRIFTS of modified montmorillonite clay catalysts were recorded using a diffuse reflectance accessory at room temperature on Nicolet Avatar 320 FT-IR spectrometer. The modified montmorillonite clay catalysts were dried in a hot air oven for $1 \mathrm{~h}$ at $100{ }^{\circ} \mathrm{C}$ prior to pyridine treatment for IR measurements. The catalyst samples ( $\sim 50 \mathrm{mg}$ each) were poured loosely into a sample cup. The loosely filled sample was brought in contact with pyridine $\left(\sim 0.1 \mathrm{~cm}^{3}\right)$ directly. Then the sample cup was kept in a hot air oven at $120^{\circ} \mathrm{C}$ for $1 \mathrm{~h}$ to remove physisorbed pyridine. After cooling the catalyst sample, the IR spectrum was recorded in the spectral range 1650 and $1350 \mathrm{~cm}^{-1}$ with 256 scans and at a resolution of $4 \mathrm{~cm}^{-1}$ using $\mathrm{KBr}$ background.

\section{Results and discussion}

Table 1 presents the basal spacing, specific surface area, and activity of different montmorillonite clay catalysts. The basal spacing values of Raw-Mont and some modified forms such as $\mathrm{Al}^{3+}$-Mont (100), $\mathrm{Al}^{3+}$-Mont (200), $\mathrm{H}^{+}$-Mont and Al-PILC (100) are found to be in same order between 14.7 and $15.7 \AA$. The $\mathrm{Al}^{3+}$-Mont (400) showed absence of $d_{0} 01$ plane indicating layered structure collapse on thermal treatment of $\mathrm{Al}^{3+}$-Mont at $400{ }^{\circ} \mathrm{C}$. However, $\mathrm{Al}$ PILC (500) showed characteristic intense peak for $d_{0} 01$ plane with basal spacing $17.5 \AA$. Also as expected the specific surface area values are low (21-34 $\left.\mathrm{m}^{2} \mathrm{~g}^{-1}\right)$ and of same order for Raw-Mont and some modified forms such as $\mathrm{Al}^{3+}$-Mont (100), $\mathrm{Al}^{3+}$-Mont (200), $\mathrm{Al}^{3+}$-Mont (400), $\mathrm{H}^{+}$-Mont and Al-PILC (100) catalysts.

\section{Table 1}

Basal spacing, specific surface area, and activity $^{\mathrm{a}}$ of montmorillonite clay catalysts

\begin{tabular}{|c|c|c|c|}
\hline Catalyst & Basal spacing $(\AA)$ & Surface area $\left(\mathrm{m}^{2} \mathrm{~g}^{-1}\right)$ & Ester yield $(\%)^{b}$ \\
\hline Blank (no catalyst) & - & - & Nil \\
\hline Raw-Mont & 14.7 & 20.9 & Nil \\
\hline $\mathrm{Al}^{3+}$-Mont (100) & 15.5 & 22.8 & 88 \\
\hline $\mathrm{Al}^{3+}$-Mont (200) & 15.5 & 36.2 & 56 \\
\hline $\mathrm{Al}^{3+}$-Mont (400) & $d_{001}$ peak absent & 35.4 & Nil \\
\hline Al-PILC (100) & 15.7 & 22.2 & Nil \\
\hline Al-PILC (500) & 17.5 & 201.0 & Nil \\
\hline $\mathrm{H}^{+}$-Mont & 15.1 & 30.7 & 85 \\
\hline Mont K-10 & $d_{001}$ peak absent & 254.0 & 19 \\
\hline $\mathrm{Al}^{3+}$-Mont $\mathrm{K}-10$ & - & 267.0 & 52 \\
\hline
\end{tabular}

a Concentration of propionic acid, $5 \mathrm{mmol}$; concentration of $p$-cresol, $15 \mathrm{mmol}$; amount of catalyst, $0.5 \mathrm{~g}$; solvent, toluene $(35 \mathrm{~mL})$; reaction time, $8 \mathrm{~h}$.

b Isolated yields. 


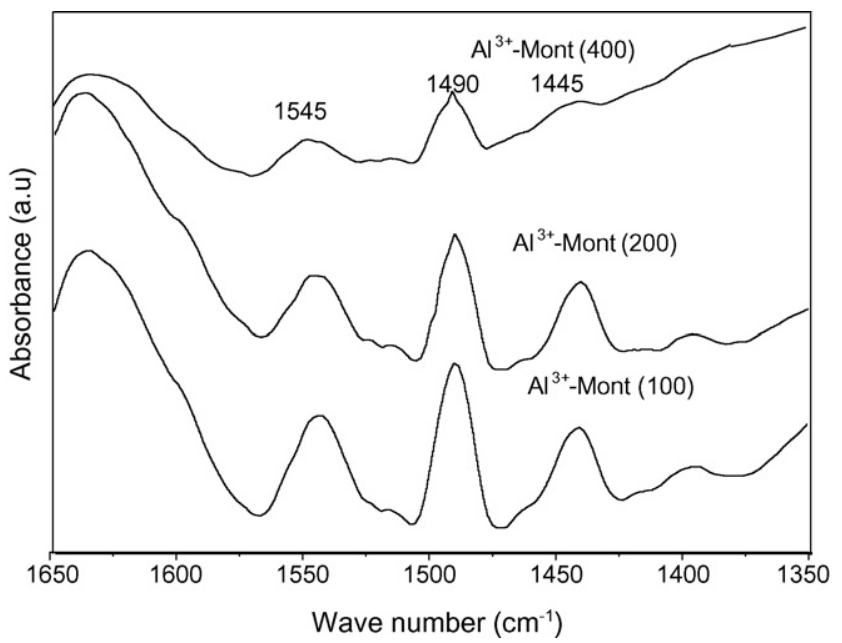

Fig. 1. DRIFT spectra of pyridine treated $\mathrm{Al}^{3+}$-Mont (100), $\mathrm{Al}^{3+}$-Mont (200), and $\mathrm{Al}^{3+}$ Mont (400) clay catalysts.

The Al-PILC (500) showed characteristic high surface area $\left(201 \mathrm{~m}^{2} \mathrm{~g}^{-1}\right)$. Commercial acid clay, montmorillonite $\mathrm{K}-10$ and its $\mathrm{Al}^{3+}$-exchanged form also showed high specific surface area $\left(254-267 \mathrm{~m}^{2} \mathrm{~g}^{-1}\right)$.

The catalytic activities of montmorillonite clay catalysts in the esterification of propionic acid with $p$-cresol are presented in Table 1.

The DRIFT spectra in the spectral region 1350 and $1650 \mathrm{~cm}^{-1}$ after pyridine treatment of modified clay catalysts followed by thermal desorption at $120^{\circ} \mathrm{C}$ for $1 \mathrm{~h}$ are presented in Figs. $1-4$. The IR absorption bands are assigned according to Breen et al. [8]. Physisorbed pyridine was assigned to the bands at $\sim 1577$ and $\sim 1440 \mathrm{~cm}^{-1}$; hydrogen-bonded pyridine to $\sim 1440$ and $1590 \mathrm{~cm}^{-1}$; Lewis acid-bound pyridine to $\sim 1450,1490,1590$ and $1620 \mathrm{~cm}^{-1}$; pyridine coordinated through its aromatic $\pi$ electrons to $\sim 1607 \mathrm{~cm}^{-1}$, and the Brønsted acid-bound pyridinium cation to $\sim 1540$ and $1640 \mathrm{~cm}^{-1}$. The spectra of modified montmorillonite clay catalysts exhibit major absorption bands similar to those observed by Jankovic and Komadel [9]. Spectra of all samples both before and after pyridine treatment show broad absorption band at $\sim 1640 \mathrm{~cm}^{-1}$ due to bending vibrations of $-\mathrm{OH}$ group of water molecules. However, there were no other absorption bands for clay catalyst samples before pyridine treatment except $1640 \mathrm{~cm}^{-1}$ band. Since the samples were subjected to thermal desorption at $120{ }^{\circ} \mathrm{C}$ before taking the spectra, they show

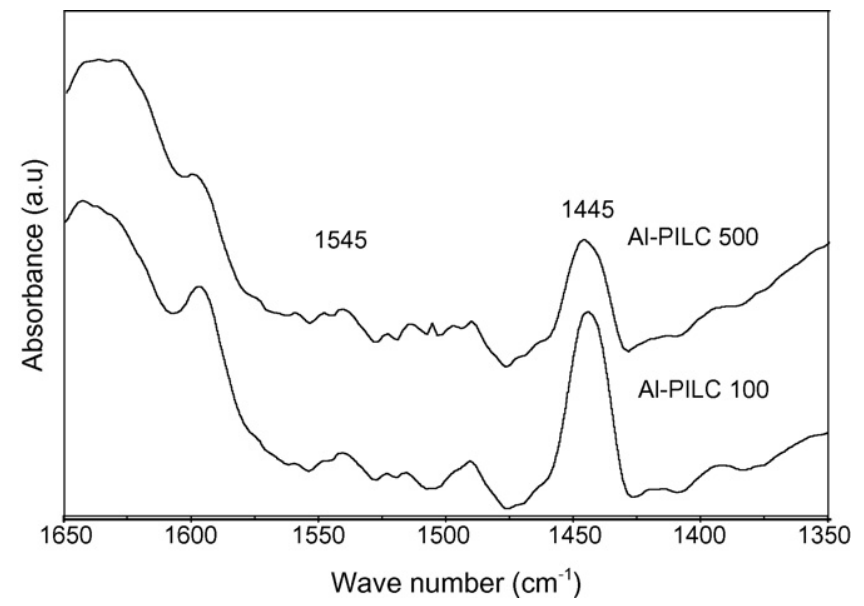

Fig. 2. DRIFT spectra of pyridine treated Al-PILC (100) and Al-PILC (500) catalysts.

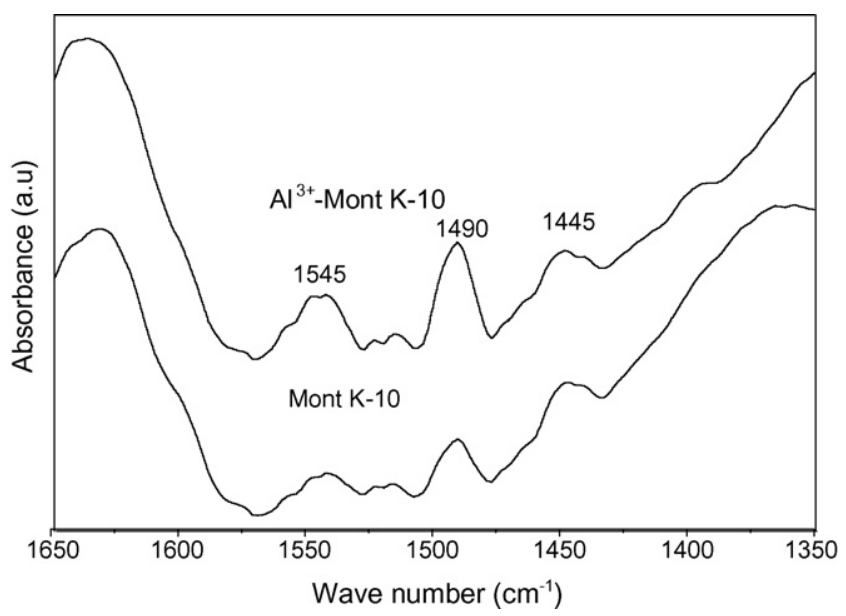

Fig. 3. DRIFT spectra of pyridine adsorbed on Mont $\mathrm{K}-10$ and $\mathrm{Al}^{3+}$-Mont $\mathrm{K}-10$ catalysts.

the absence of physisorbed pyridine (band at $\sim 1577$ and $\sim 1440 \mathrm{~cm}^{-1}$ ) and hydrogen bonded pyridine (band at $\sim 1440$ and $\sim 1590 \mathrm{~cm}^{-1}$ ) that are otherwise observed. The catalyst samples did not show any color changes on pyridine treatment and/or on heat treatment. The DRIFT spectral and activity results of montmorillonite clay catalysts are presented under different headings.

\subsection{DRIFT spectra of $\mathrm{Al}^{3+}$-Mont catalysts}

The DRIFT spectra of pyridine treated $\mathrm{Al}^{3+}$-Mont (100), $\mathrm{Al}^{3+}$ Mont (200), and $\mathrm{Al}^{3+}$-Mont (400) clay catalysts are presented in Fig. 1. The spectra of these catalysts show three major absorption bands at 1545,1490 , and $1450 \mathrm{~cm}^{-1}$ corresponding to Brønsted, both Brønsted and Lewis, and Lewis acidity respectively. Among these three catalysts, $\mathrm{Al}^{3+}$-Mont (100) showed a slightly more intense absorption bands compared to $\mathrm{Al}^{3+}$-Mont (200), which in turn was more intense compared to $\mathrm{Al}^{3+}$-Mont (400). On thermal treatment at $200{ }^{\circ} \mathrm{C}$ the spectrum of $\mathrm{Al}^{3+}$-Mont (200) indicates slight reduction in the intensity of the peaks of both Brønsted and Lewis acidity. Further, the spectrum of $\mathrm{Al}^{3+}$-Mont (400) reflects the destruction of both Brønsted and Lewis acidity to a larger extent on thermal treatment at $400{ }^{\circ} \mathrm{C}$. The intensity of absorption band at $\sim 1545 \mathrm{~cm}^{-1}$, specifically, is high in the case of $\mathrm{Al}^{3+}$-Mont (100) indicating presence of Brønsted acidity in high concentration. The intensity reduces for the sample thermally treated at $200{ }^{\circ} \mathrm{C}$ and becomes almost negligible for that treated at $400{ }^{\circ} \mathrm{C}$.

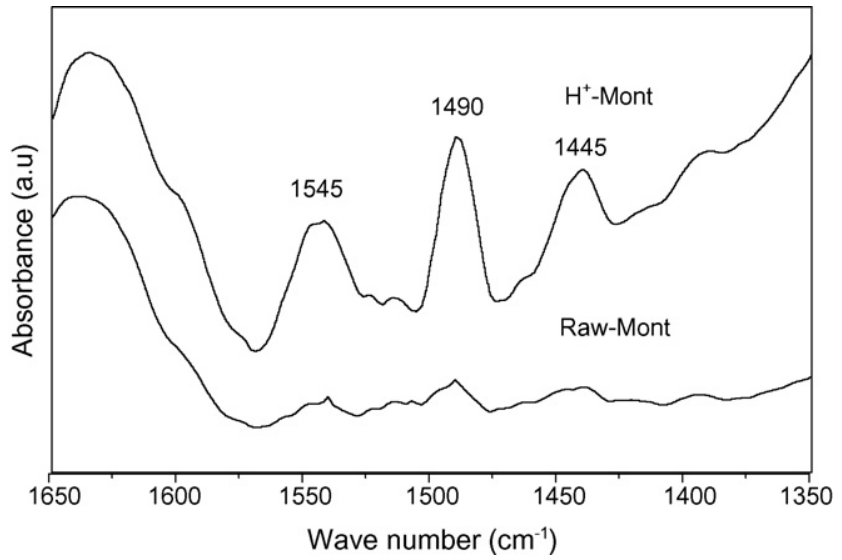

Fig. 4. DRIFT spectra of pyridine adsorbed on Raw-Mont and $\mathrm{H}^{+}$-Mont clay catalysts. 
The observed variations in Brønsted acidity concentration are reflected in their activity in the esterification of propionic acid with p-cresol (Table 1). A very good activity ( $88 \%$ ester yield) observed with $\mathrm{Al}^{3+}$-Mont (100) is attributed to its higher Brønsted acidity as shown by the intensity of the peak at $1545 \mathrm{~cm}^{-1}$. Similarly the reduced activity (56\% ester yield) in case of $\mathrm{Al}^{3+}$-Mont (200) is attributed to its reduced Brønsted acidity as shown by the peak at $1545 \mathrm{~cm}^{-1}$. Negligible activity was observed in the case of $\mathrm{Al}^{3+}$ Mont (400) due to its insignificant Brønsted acidity. The reduced activity due to insignificant Brønsted acidity of $\mathrm{Al}^{3+}$-Mont upon thermal treatment beyond $200{ }^{\circ} \mathrm{C}$ is obviously due to the loss of water molecules attached to the hydration shell of the cation [7,21]. Similar relationship was observed in esterification of succinic acid with iso-butyl alcohol and DRIFT spectra for $\mathrm{Al}^{3+}$ exchanged montmorillonite clay catalyst [22].

\subsection{DRIFT spectra of Al-PILC}

The DRIFT spectra of pyridine treated Al-PILC (100) and Al-PILC (500) clay catalysts are presented in Fig. 2. Both the samples show only one prominent absorption band at $1450 \mathrm{~cm}^{-1}$ and very feeble bands at 1545 and $1490 \mathrm{~cm}^{-1}$ indicating low concentration of the Brønsted acidity and significant amount of Lewis acidity. Also both the catalysts failed to give ester when used in esterification of propionic acid with $p$-cresol. The inactivity of catalysts is due to the absence of Brønsted acidity and that the Lewis acidity although present in high concentration, apparently, does not catalyze the esterification. Pillared montmorillonite clays are known to exhibit high Lewis acidity [23].

\subsection{DRIFT spectra of Mont $\mathrm{K}-10$ and $\mathrm{Al}^{3+}$-Mont $\mathrm{K}-10$}

The DRIFT spectra of pyridine treated Mont K-10 and $\mathrm{Al}^{3+}$-Mont K-10 clay catalysts are presented in Fig. 3 . The spectra of these catalysts also exhibited weak absorption bands at 1545, 1490, and $1450 \mathrm{~cm}^{-1}$ indicating presence of both Brønsted and Lewis acidity in low concentrations. Of the two catalysts, aluminium-exchanged montmorillonite $\mathrm{K}-10$ ( $\mathrm{Al}^{3+}$-Mont $\left.\mathrm{K}-10\right)$ displayed slightly more intense absorption bands compared to the parent clay, Mont K-10. Cation exchange of Mont K-10 has apparently resulted in the enhancement of both Brønsted and Lewis acidity. The activity of the Mont K-10 catalyst was also observed to be low as only $19 \%$ yield of product was obtained when used in the esterification. The $\mathrm{Al}^{3+}$-exchanged Mont $\mathrm{K}-10\left(\mathrm{Al}^{3+}\right.$-Mont $\left.\mathrm{K}-10\right)$ showed increased activity with $52 \%$ ester yield which could be attributed to its enhanced Brønsted acidity by the inclusion of $\mathrm{Al}^{3+}$. However, the increase in ester yield was not very significant compared to the yield obtained using $\mathrm{Al}^{3+}$-exchanged form of Raw-montmorillonite. The reason for this observation may be due to the reduced cation exchange capacity of Mont K-10 [24].

\subsection{DRIFT spectra of Raw- and $\mathrm{H}^{+}$-Mont}

The DRIFT spectra of pyridine treated $\mathrm{H}^{+}$- and Raw-Mont clay samples are presented in Fig. 4. The spectra of $\mathrm{H}^{+}$-Mont observed to be similar to that of $\mathrm{Al}^{3+}$-Mont catalyst with respect to intensity of absorption bands at 1450,1490 and $1540 \mathrm{~cm}^{-1}$. Acid treatment of clays is known to result in the removal of $\mathrm{Al}^{3+}$-ions from the octahedral sheet and possibly other soluble ions which subsequently migrate into the interlayer $[25,26]$. The spectrum of $\mathrm{H}^{+}$Mont indicates presence of both Brønsted and Lewis acidities to the same extent as $\mathrm{Al}^{3+}$-Mont. Also, the activity of $\mathrm{H}^{+}$-Mont was observed to be high ( $85 \%$ ester yield) and is in the order observed for $\mathrm{Al}^{3+}$-Mont. The Raw-Mont in its $\mathrm{Na}^{+}$-form exhibited absence of all those absorption bands observed for its modified forms. However the sample revealed a broad absorption band at $1640 \mathrm{~cm}^{-1}$, which is due to bending vibrations of $-\mathrm{OH}$ group of water associated with the clay surface. The results of surface acidity measurements by DRIFTS using pyridine probe indicated that the modified forms of clay exhibited better Brønsted and Lewis acidity as compared to its natural form.

\section{Conclusion}

A simplified method of acidity determination is found to give well resolved and reproducible DRIFT spectra arising from the interaction of pyridine with Brønsted and Lewis acid sites on the surface of montmorillonite. The intensity of peak due to Brønsted acidity $\left(1545 \mathrm{~cm}^{-1}\right)$ correlated well with the activity of the modified montmorillonite catalysts for the esterification of propionic acid with $p$-cresol. The decrease in the area of the Brønsted peaks with the thermal treatment and consequent reduction in the activity of the Al-exchanged montmorillonite clearly demonstrates the role played by the interlamellar water coordinated to the metal ions in the esterificaton. The water molecules coordinated to the exchangeable $\mathrm{Al}^{3+}$-ions dissociate generating the Brønsted acid sites which in turn are able to protonate the carboxylic acid to effect esterification. Aluminium pillared clay fail to bring esterification due to very low intensity peak for Brønsted acidity and strong peak for Lewis acidity. A simple approach developed here for acidity measurement can be advantageously used for a quick evaluation of Brønsted acidity of layered materials where interlamellar water determines the acidity.

\section{Acknowledgment}

The authors wish to express their grateful thanks to the Members of the Governing Council of Bangalore Institute of Technology for the laboratory facilities provided.

\section{References}

[1] H. Kawakami, S. Yoshida, T. Yonezawa, J. Chem. Soc. Faraday Trans. 80 (1984) 205

[2] J.A. Lercher, C. Grundling, G. Eder-Mirth, Catal. Today 27 (1996) 353.

[3] V. Bolis, G. Cerrato, G. Mangnacca, Morterra, Thermochim. Acta 312 (1998) 63.

[4] F. Flade, Z. Pysik. Chem. 76 (1911) 513.

[5] H.A. Benesi, J. Phys. Chem. 61 (1957) 970

[6] H.P. Hart, D.R. Brown, J. Mol. Catal. A 212 (2004) 315.

[7] D.R. Brown, C.N. Rhodes, Catal. Lett. 45 (1997) 35.

[8] C. Breen, A.T. Deane, J.J. Flynn, Clay Miner. 22 (1987) 169.

[9] L. Jankovic, P. Komadel, J. Catal. 218 (2003) 227.

[10] C. Breen, Clay Miner. 26 (1991) 473.

[11] M. Guisnet, in: B. Imelik, C. Naccache, G. Coudurier, Y.B. Taarit, J.C. Vedrine (Eds.), Studies in Surface Science and Catalysis, vol. 20, Elsevier, Amsterdam, 1985, p. 283.

[12] M. Trombetta, G. Busca, M. Lenarda, L. Storaro, R. Ganzerla, L. Piovesan, A.J. Lopez, M.A. Rodriguez, E.R. Castellon, Appl. Catal. A 193 (2000) 55.

[13] U. Flessner, D.J. Jones, J. Rozierre, J. Zajac, L. Storaro, M. Lenarda, M. Pavan, A.J. Lopez, E.R. Castellon, M. Trombetta, G. Busca, J. Mol. Catal. A 168 (2001) 247.

[14] E.P. Parry, J. Catal. 2 (1963) 371

[15] C.A. Emeis, J. Catal. 141 (1993) 347.

[16] S. Bodoardo, F. Figueras, E. Garrone, J. Catal. 147 (1994) 223.

[17] R. Mokaya, W. Jones, J. Catal. 172 (1997) 211.

[18] J.M. Adams, D.E. Clement, S.H. Graham, Clays Clay Miner. 3 (1983) 129.

[19] S. Selvaraj, B.V. Mohan, K.N. Krishna, B.S. Jai Prakash, Appl. Clay Sci. 10 (1996) 439.

[20] R.A. Schoonheydt, H. Leeman, A. Scorpion, I. Lenotte, P. Grobet, Clays Clay Miner. 42 (1994) 518.

[21] C. Ravindra Reddy, B. Vijayakumar, P. Iyengar, G. Nagendrappa, B.S. Jai Prakash, J. Mol. Catal. A 223 (2004) 117.

[22] C. Ravindra Reddy, G. Nagendrappa, B.S. Jai Prakash, Catal. Commun. 8(2007) 241.

[23] M.L. Occelli, R.M. Tindwa, Clays Clay Miner. 31 (1983) 22.

[24] D.R. Taylor, D.B. Jenkins, Soc. Min. Eng. AIME Trans. 282 (1986) 1901.

[25] C.N. Rhodes, D.R. Brown, J. Chem. Soc. Faraday 91 (1995) 1031.

[26] R.D. Heyding, R. Ironside, A.R. Norris, R.Y. Prysiazniuk, Can. J. Chem. 38 (1960) 1003. 